\title{
Study for High-Efficient Microbial Flocculent and its Application in Wastewater Treatment
}

\author{
Yong Zhang ${ }^{*}$, Jian Song $^{1}$, Jian Huang ${ }^{1}$ and Hualin Zhang $^{2}$ \\ ${ }^{I}$ School of Environment and Energy Engineering, Anhui Jianzhu University, Hefei 230022, China \\ ${ }^{2}$ Bureau of Housing and Urban-Rural Development of Kunshan City, Kunshan 215300, China
}

\begin{abstract}
Objective: More and more non-degradable substances in wastewater along change of life style, however, traditional handling agent has not met the demand of wastewater treatment, so it is very important to study for new highefficient flocculent. Method: Sifting out six microbes after testing and inoculation, and then testing for wastewater quality having three contents, this found that mix bacteria had better effect than $1 \#$ microbe at time of separate use, mix bacteria $1 \#$ microbe are dominant, and also discussed with external advantage influencing on flocculent. Conclusion: $1 \#$ microbe has the best effect of flocculent for three wastewater, respectively as $91.2 \%$ (A wastewater), $80.5 \%$ (B wastewater) and $80.5 \%$ (C wastewater).
\end{abstract}

Keywords: Flocculent, high efficiency, microbe, wastewater treatment.

\section{INTRODUCTION}

Water pollution mainly sources from industrial wastewater and living one after drainage, traditional inorganic flocculent and organic macromolecular flocculent both play important role in wastewater treatment. However, each inorganic flocculent and organic macromolecular flocculent easily results in Alzheimer's disease and ThreeZhi Effect found in the course of use, meanwhile some issues such as high cost, limited flocculent effect and difficulty handling sludge remained still exist; along with broad use of them, gradually reflecting hazard and traditional technique and method difficultly meets the requirements from multifunctional, hi-efficient and reasonable wastewater treatment. Hereby, seeking for hi-efficient, safe and environment-friendly microbial flocculent and meeting safe use of flocculent and reduces second pollution during wastewater treatment will be extensively prosperous for development. Technique and technical method developed, studied and applied for new wastewater treatment has been focused by researchers in international wastewater pollution control engineering industry all over the world. Along with extensive and deep study for microbial technology, reducing production cost of microbial flocculent and probing hiefficient microbial flocculent bacteria specimen shall be key content in further study [1].

\section{MICROBIAL FLOCCULENT}

Microbial flocculent is one of flocculent and activated secondary metabolite created by microbe, and it also is one kind of substances after difficult-sediment solid suspending particle flocculates and sediments, it is one kind of safe, high-efficient and naturally degradable new wastewater treatment agent obtained from microbe or its secreta after extraction and purified under biological technology [2]. Microbial flocculent includes three kinds, (1) flocculent directly using microbial cell, (2) flocculent that extracts by microbial cell wall, (3) flocculent by use of cell metabolite. Since microbial flocculent takes advantage of highefficiency, safety and non-toxicity, none second pollution, extensive use and relatively less pouring and so forth, they are better treatment with most of living wastewater and some industrial one.

\section{FLOCCULENT MECHANISM}

Pour some flocculent into water and increase in contraion concentration in water so as to make some contra-ion extend into absorption layer from diffusion one; after adding up flocculent to critical concentration, idiozome will flocculate; well-neutralized particles collide and create flocculation while absorptive polymer contacts with stable idiozome diffusive system, group shall specially absorb idiozome surface while high polymer contacts with idiozome, however, the rest may absorb the other idiozome and form into idiozome-macromolecule-idiozome as flocculent body; make little idiozome in water into flocculent while adding up more flocculent, absorb each other and accompany bridging, finally form into relatively bigger flocculation body, sediment down under gravity.

\section{TESTING INSTRUMENT AND METHOD}

\subsection{Testing Instrument and Reagent}

Testing instrument: COD reactor, HACH-DR/890 chromometer, hi-pressure vapor bacteria pot, temperatureconstant drier, electric stove, magnetic mixer, optical microscope, electronic balance, centrifugal machine, PHS- 
3C meter, ultraviolet lamp, and little oxygen filling machine and so forth.

Key reagent: beef paste (biochemical reagent), peptone (biochemical reagent), yeast extract (biochemical reagent), (biochemical reagent), agar (biochemical reagent), white bole (testing reagent). The rest reagents are used from analytical reagent.

Cane sugar $\quad \mathrm{NaNO}_{3} ; \quad \mathrm{K}_{2} \mathrm{HPO}_{4} ; \quad \mathrm{FeSO}_{4} ; \quad \mathrm{KCl}$; $\mathrm{MgSO}_{4} \cdot 7 \mathrm{H}_{2} \mathrm{O}$; grape sugar; $\left(\mathrm{NH}_{4}\right)_{2} \mathrm{SO}_{4}$; urea; $\mathrm{KH}_{2} \mathrm{PO}_{4}$; $\mathrm{NaCl}$; soluble starch; $\mathrm{KNO}_{3} ; \mathrm{NH}_{4} \mathrm{Cl}$; caustic soda; dilute hydrochloric acid; non-water calcium chloride.

\subsection{Test Method}

\subsubsection{Microbial Preparation}

Test applies for culture media (yeast extract), after its sterilization and disinfection, vaccinate and cultivate it onto six culture vessel, and then suck little A active sludge (from wastewater treatment plant) by non-bacteria sucker, and pour into little measuring glass, then dilute it by non-bacteria vapor and shake evenly and silently place it for vaccinate it; after vaccination, turn upside down it onto still table, finally cultivate it for two or three days under indoor temperature [4]. Observe culture vessel after cultivation for two or three days, and sift and purify it for cultivation, test and separate into six microbes, respectively coding them into $1 \#, 2 \#, 3 \#$, 4\#, 5\# and 6\#.

Purify and extensively cultivate for six microbes, sift out the best microbe with best wastewater treatment. Respectively and extensively cultivate six microbes for two or three days, at time, microbe generally keeps stable growth and multiplication, namely it keeps up max intensity of microbial growth, so it has the best wastewater treatment under such condition.

\subsubsection{Sifting Optimally Flocculent Microbe}

\subsubsection{Flocculent Rate}

Respectively take A wastewater, B wastewater, C wastewater for test and study, by several tests under same condition, finally decide the best microbial bacterial specimen among three flocculent, respectively coding $1 \#, 3 \#$ or 4\#. Flocculent rate for six specimen is shown in Table $\mathbf{1}$.

Table 1. The flocculent rate to the wastewater of the six microbial flocculants.

\begin{tabular}{|c|c|c|c|c|c|c|}
\hline \multirow{2}{*}{$\begin{array}{c}\text { Wastewater } \\
\text { Source }\end{array}$} & \multicolumn{5}{|c|}{ Flocculent Efficiency (\%) for Wastewater } \\
\cline { 2 - 7 } & $\mathbf{1 \#}$ & $\mathbf{2 \#}$ & $\mathbf{3 \#}$ & $\mathbf{4 \#}$ & $\mathbf{5 \#}$ & $\mathbf{6 \#}$ \\
\hline \hline A wastewater & 91.5 & 67.7 & 75.8 & 70.8 & 23.9 & 38.5 \\
\hline B wastewater & 87.3 & 58.9 & 72.6 & 62.1 & 38.4 & 44.8 \\
\hline C wastewater & 91.3 & 68.3 & 80.4 & 60.0 & 29.1 & 55.1 \\
\hline
\end{tabular}

\subsubsection{Identification of Advantageous Microbe}

Make microbial growth curve for $1 \#, 3 \#$ or $4 \#$ activated microbe: act $\log$ value of cell number as $\mathrm{Y}$-axis, and cultivation time as $\mathrm{X}$-axis before making regular curve.
Up to growth rate (constant) of microbe, namely crack algebra per hour, generally classify typical growth curve into four periods such as adoption period, index growth period, stabilization period and decay period. For the test and under same condition (temperature, $\mathrm{pH}$, culture media), take three types of well-diluted one-bacteria liquid, and respectively vaccinate into liquid culture media with yeast extract for extension and cultivation, and then measure total cell in regular period. Measuring method may be used by diluting flat count method. While measuring it $96 \mathrm{~h}$ later, stop measuring. Actual growth curve for flocculent activated bacteria (1\#, 3\# and 4\#) is shown in Fig. (1).

Micro concentration sequence during cultivation is $1 \#>$ $4 \#>3 \#$, the time it reaches the max concentration lasts for 24 to $30 \mathrm{~h}$. Before it reaches max concentration, microbe keeps up index growth, cell divides fast. Growth trends are similar in three microbes. Generally speaking, growth rule and trend reflected from these three microbes are compliant.

\subsection{Analysis for Wastewater Treatment Rate}

During wastewater treatment, flocculent rate is used to express wastewater treatment. The flocculent rate represents wastewater treatment, the higher flocculent rate expresses the more pollutant treated in wastewater, and the better treatment; the lower flocculent rate, the worse treatment [6].

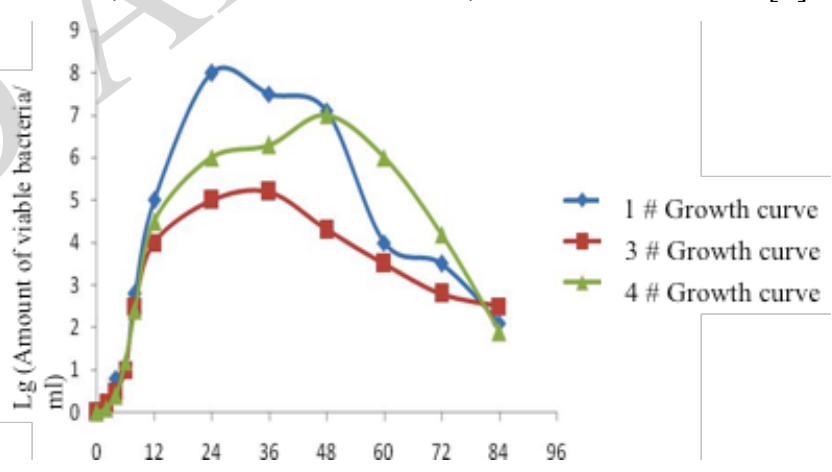

Fig. (1). The growth curve of the microbe.

Under same test condition, take each quantity-same microbial flocculent or its mix liquid, then respectively test wastewater treatment for three wastewater. Finally make analysis for removal efficiency from three microbial flocculent activated bacteria (1\#, 3\# or 4\#).

\subsubsection{One-Bacteria Treatment Rate}

Treatment rate of one-bacteria microbial flocculent (1\#, $3 \#$ or $4 \#$ ) with A wastewater, B wastewater and C wastewater under optimal treatment is shown in Figs. (2-4).

Figs. (2-4) indicated that flocculent rate of $1 \#$ microbe for wastewater was $10.5 \% \sim 91.2 \%$, that of $2 \#$ microbe for wastewater was $8.9 \% \sim 80.3 \%$, that of $4 \#$ for wastewater was $8.6 \% \sim 75.4 \%$. microbial flocculent (1\#, 3\# or $4 \#)$ was similar flocculent curve for A wastewater and B wastewater, three one-bacteria microbes has rising flocculent rate along with time for $\mathrm{C}$ wastewater. Hereby, in a word, microbial flocculent rate was $1 \#>3 \#>4 \#$; and flocculent rate of microbe for wastewater also change with wastewater quality. 


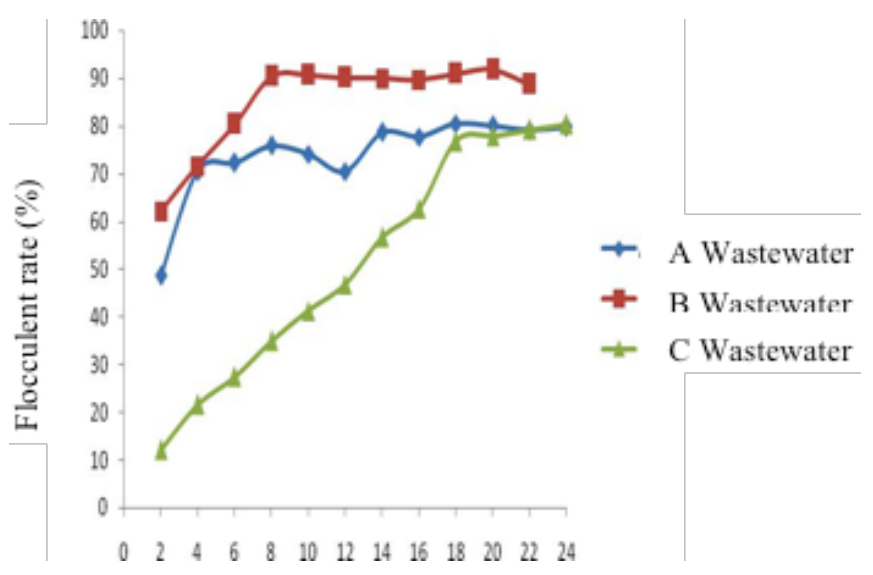

Fig. (2). The relation between flocculent rate and time of $1 \#$ microbial.
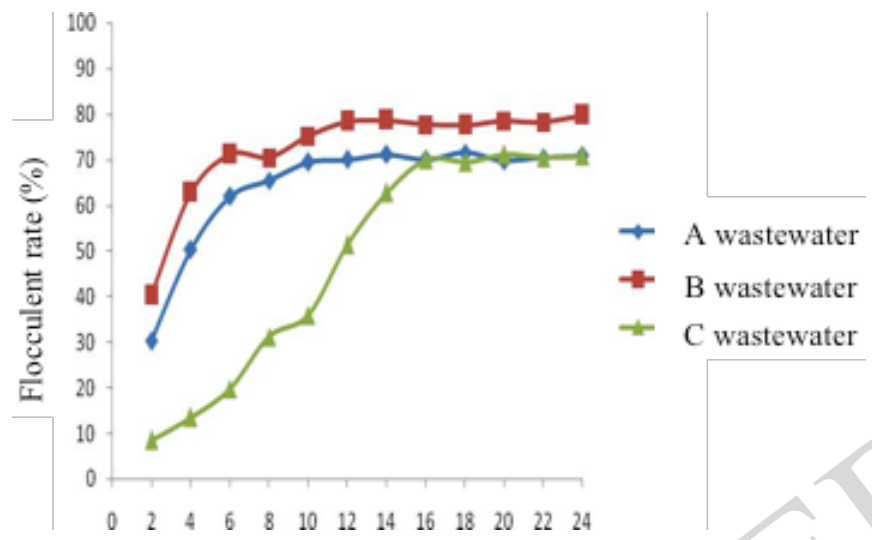

Fig. (3). The relation between flocculent rate and time of $3 \#$ microbial.

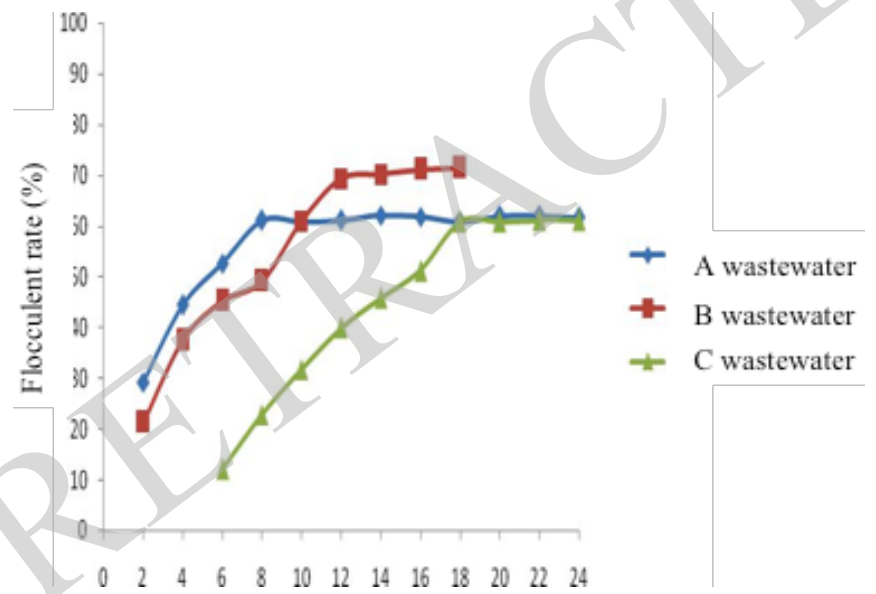

Fig. (4). The relation between flocculent rate and time of $4 \#$ microbe.

\subsubsection{Treatment Rate of Mix Bacteria}

Mix $1 \#$ with $3 \#$, mix $1 \#$ with $4 \#$, mix $3 \#$ with $4 \#$, and mix $1 \#$ with $3 \#$ or $4 \#$ under equal dose, make them into four microbial mix flocculent, respectively make flocculent test for $\mathrm{A}, \mathrm{B}, \mathrm{C}$ wastewater, map up time-flocculent rate curve.

Wherein, flocculent result for A wastewater is shown in Fig. (5).

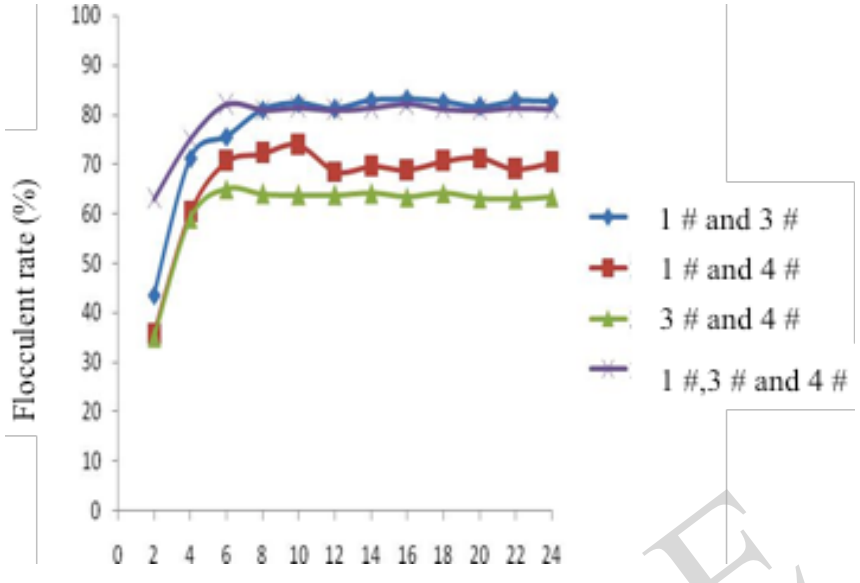

Fig. (5). The relation between flocculent rate and time.

Flocculent rate for B wastewater is shown in Fig. (6).

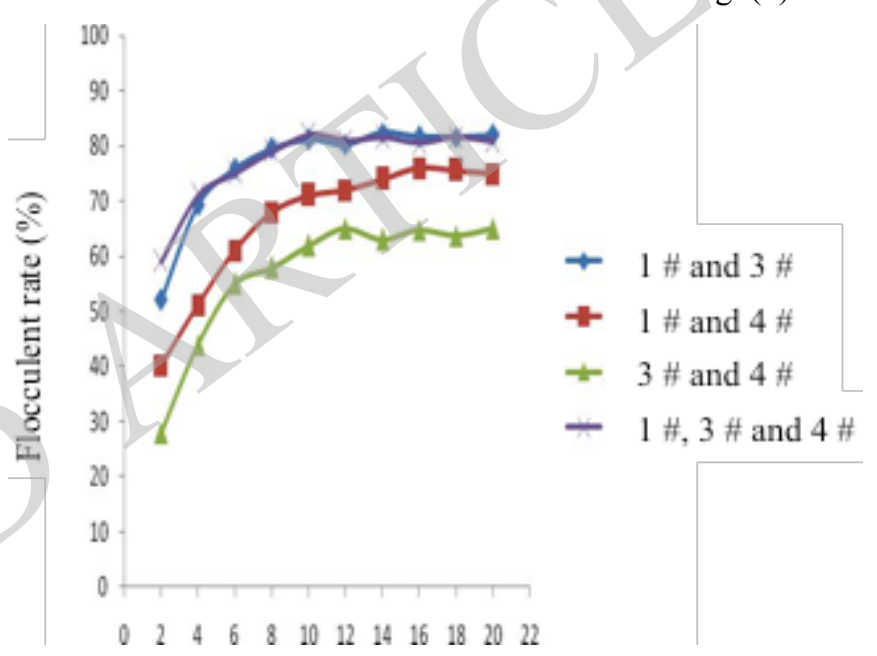

Fig. (6). The relation between flocculent rate and time.

Flocculent rate for $\mathrm{C}$ wastewater is shown in Fig. (7).

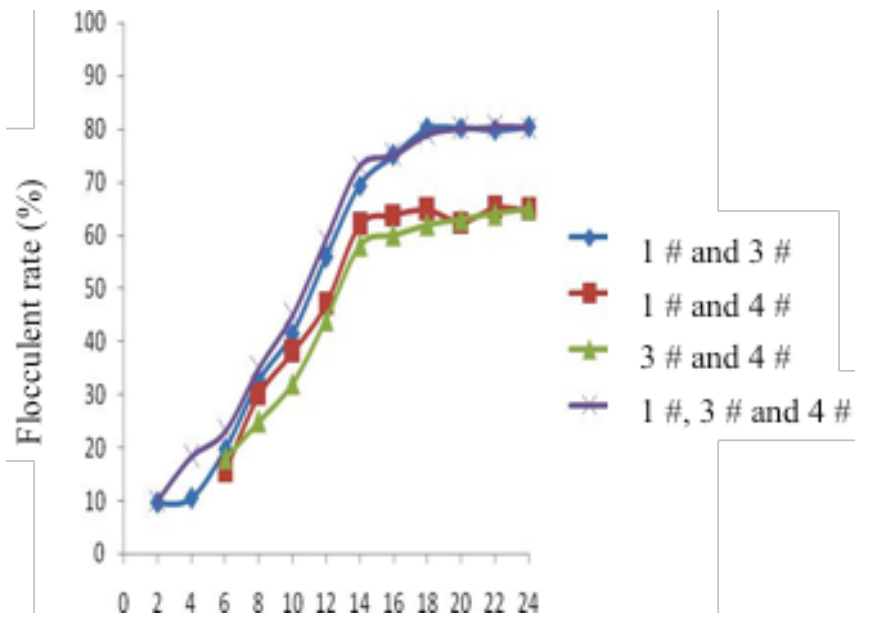

Fig. (7). The relation between flocculent rate and time.

Fig. (5) indicated that rate of after-mixed $1 \#$ and $3 \#$ microbe stays between rate of separately used $1 \#$ microbe and $3 \#$ microbe; rate of after-mixed $1 \#$ and $4 \#$ microbe stays between rate of separately used $1 \#$ microbe or $4 \#$ microbe, rate of after- mixed $3 \#$ and $4 \#$ microbe is same as rate of 
separately used $4 \#$ microbe. However, in a word, as 1\# microbial treatment rate is better than other two, so mix bacteria having $1 \#$ microbe is more than that of none $1 \#$ microbe. Flocculent rate of each mix bacteria for $\mathrm{A}$ wastewater and $\mathrm{B}$ wastewater both are higher than that for $\mathrm{C}$ wastewater.

It is explained that, after adding up $3 \#$ microbe, this still can't improve wastewater treatment of $1 \#$ flocculent microbe, their treatment is independently done; after adding up 4\# microbe, this still cannot improve wastewater treatment of $1 \#$ flocculent microbe, their treatment is basically and independently done without any obvious influence.

Mix result for three bacteria indicated that microbe for three bacteria is relatively higher than that of $1 \#$ and $3 \#$ microbe, and $1 \#$ and $3 \#$ mix bacteria is higher than that of $1 \#$ and $4 \#$, but that of $3 \#$ or $4 \# \operatorname{mix}$ bacteria is worst.

During wastewater treatment, it is the best for wastewater treatment by flocculent created after separately using $1 \#$ microbe, it is highest flocculent rate after wastewater treatment: that of $\mathrm{A}$ wastewater is $91.2 \%$, that of $\mathrm{B}$ wastewater is $80.5 \%$ and $\mathrm{C}$ wastewater is $80.3 \%$. Treatment is much better than it optionally combines with other two hi-efficient microbial flocculent (3\# microbe and $4 \#$ microbe), and also higher than that of $3 \#$ microbe or $4 \#$ microbe if separately used. In a word, some test study indicated that, $1 \#$ is the best bacteria that creates microbial flocculent for wastewater treatment. Such hi-efficient flocculation closely relates with inherent growth property, flocculation process during wastewater relates with several factors, mainly relates with concentration of microbial flocculent, activation, metabolic rate and resolution rate of organics [7].

\subsection{Influential Facto for Treatment Rate}

\subsubsection{Influence of PH for Flocculation Rate}

$\mathrm{PH}$ is the best for culture media if it is $6.5 \sim 8.0$ for such scope, microbial flocculation is optimal because microbial activation is the strongest at such scope, and microbial degradation of organics is the fastest, meanwhile it also benefits for growth and multiplication for microbe itself [8].

\subsubsection{Influence of Temperature for Flocculent Rate}

$30^{\circ} \mathrm{C}$ is the best generally, since $1 \#$ microbe is fastest growth and multiplication under such temperature, eozymes was the strongest activation and best benefit for creation of flocculent [9]. However, too low temperature will reduce eozymes activation for microbe; too high temperature will reduce eozymes activation for microbe or lost activation for microbe, so too low or high temperature both can reduce growth and multiplication of microbe, accordingly reduce flocculent microbial quantity or flocculent substance. Therefore, microbial cultivation temperature generally is kept at $30^{\circ} \mathrm{C}$ or so during wastewater treatment under biological method [10].

\subsubsection{Influence of Flocculent Time for Flocculent Rate}

Wastewater content and ingredient also is different as wastewater quality is different, which results in different optimal flocculent time, pollution ingredient is relatively simpler and basically is organic substance, so the best flocculent time is also relatively shorter.

\subsubsection{Influence of Pouring for Flocculent Rate}

In case if pouring less flocculent, its resolution for organics and foreign matter in flocculent wastewater will last for a long time; in case if pouring more flocculent, excessive flocculent will pollute water. For each wastewater, it also results in different best pouring amount for microbial flocculent as its wastewater ingredient is different [11].

\section{CONCLUSION AND SUGGESTION}

This Article mainly elaborates separation, purification, cultivation and extensive cultivation formicrobe in activating sludge in A wastewater treatment plant, and respectively make wastewater treatment test for three wastewater selected. During study, this elaborated physical and chemical property, flocculation mechanism for selected flocculent microbial bacterial specimen and best condition at wastewater treatment.

After test, this resulted in optimal microbial flocculent bacteria $1 \#$, it is the best flocculent rate during separate use for wastewater treatment, and the highest flocculent rate respectively was $91.2 \%$ (A wastewater), $80.5 \% \quad$ (B wastewater) or $80.5 \%$ (C wastewater).

Microbial flocculent is applicably prosperous, it is expected to be hi-efficient, non-toxic, none-second polluted new-generation flocculent, however, for current study, most stay at sifting and test of bacteria specimen, beyond application for other microbial industry; regarding development and study for microbial flocculent still stays at initial phase, so this urgently needs massive employees invest more labor and capital for further development and enter into service for industrial application for flocculent in China.

\section{CONFLICT OF INTEREST}

The authors confirm that this article content has no conflict of interest.

\section{ACKNOWLEDGEMENTS}

Declared none.

\section{REFERENCES}

[1] L. Yao, "Study and its application for microbial flocculent", Hebei Chemical Engineering, vol. 33, no. 10, pp. 11-13, 2010.

[2] L. Y. Zhang, Modern environmental microbial technology. Beijing: Tsinghua University Press, 2005.

[3] Z. J. He, X. B. Gao, and Y. Li, "Applicable study for microbial flocculent and poly-aluminum muriate flocculent pig manure water", Tianjin agricultural science, vol. 14, no. 5, pp. 39-42, 2008. 
[4] S. Yue, "Applicable of microbial flocculent in waste water treatment", Journal of Xihua University (Natural science edition), vol. 25 , no.4, pp. 44-46, 2006

[5] Z. L. Liu, "Review on Regional and spatial-economic impact from high speed Rails", African journal of Business Management, vol. 6, no. 35 , pp. $9738-9741$, 2012. doi: 10.5897/ajbm12.859

[6] W. J. Liu, H. L. Yuan, and J. S. Yang, "Characterization of bioflocculants from biologically aera-ted filter backwashed sludge and its application in dying waste water treatment", Bio-resource Technology, vol. 100, no. 9, pp. 2629-2632, 2009.

[7] F. Li, X. J. Yang, and Y. P. Huang, "Microbial flocculent and its application for fuel wastewater treatment", Guangzhou Chemical Industry, vol. 38, no. 9, pp. 12-14, 2010.
[8] M. S. Huang, "Research and manufacturing of microbial flocculent and its flocculent conditions", Environmental Science, vol. 21, no. 1, pp. 23-26, 2002.

[9] C. G. Kumar, H. S. Joo, and J. W. Choi, "Purification and Characterization of an Extracellular Polysaccharide from Haloalkalophilic Bacillus sp", World Journal of Microbiology and Biotechnology, vol. 34, pp. 673-681, 2004.

[10] Y. Yang, F. Ma, N. Q. Ren, "Study for sifting and producing flocculent bacteria by biological hydrogen-made waste liquid and flocculent-creating condition", China's Supply/Drainage Water, vol. 22, no. 17, pp. 29-33, 2006 .

[11] Y. Z. Zhang, Y. G. Wu, and S. H. Hu, "Study for microbial flocculent and its application progress", Chemical Industrial Progress, vol. 27, no. 3, pp. 340-347, 2008.

(C) Zhang et al.; Licensee Bentham Open.

This is an open access article licensed under the terms of the (https://creativecommons.org/licenses/by/4.0/legalcode), which permits unrestricted, noncommercial use, distribution and reproduction in any medium, provided the work is properly cited. 